\title{
The functional anatomy of a headache - "invisible" pain displayed in colors
}

ove, happiness, sadness, pain... all impalpable, unseen and so real in our lives. We will try to display in colors the "invisible" pain via state-of-the-art imaging technology of human anatomical specimen dissections. For that, a new section named 'The Functional Anatomy of a Headache' was created in Headache Medicine (Journal of the Brazilian Headache Society) with the object of showing a relationship between anatomo-functional aspects and the genesis of facial and head pain. In the present issue a review of a relatively frequent type of "catastrophic" headache, secondary to the expansion of an aneurysm of the internal carotid artery-posterior communicating artery (ICA-PComA), was published. The ICA-PComA is the most common site of aneurysm encountered in women, whereas for men it is the second most frequent site for aneurysm. It is a known fact that during the lifespan of the individual an intracranial aneurysm will develop in up to $10 \%$ of the population. In addition, one third of intracranial aneurysms are located at ICA-PComA. The estimated frequency of third-nerve palsy in patients with ICA-PComA aneurysm is 30\% to $40 \%$ and it may evolve with periorbital pain (sentinel headache) a few days before rupture. The authors ${ }^{1}$ reviewed the anatomy of the circle of Willis, oculomotor nerve and its topographical relationships in order to better understand the pathophysiology linked to pain and thirdnerve palsy caused by an expanding ICA-PComA aneurysm.

We would like also to comment about the success of the 15th Congress of the International Headache Society that took place recently in Berlin, Germany (23-26 June, 2011 ), where we had the opportunity to come across of a number of Brazilian colleagues. Moreover, during the Congress two very special encounters occurred, with Professor James (Jim) Lance and Professor Michael Anthony (both from Australia). During a recent interview in 2010 (Interviews with Australian Scientists series, Australian Academy of Science)2 Professor Lance was asked how he had "taken the opportunity presented by patients of studying the mechanisms underlying their conditions". His answer was: "Look, there's an old saying that 'one patient

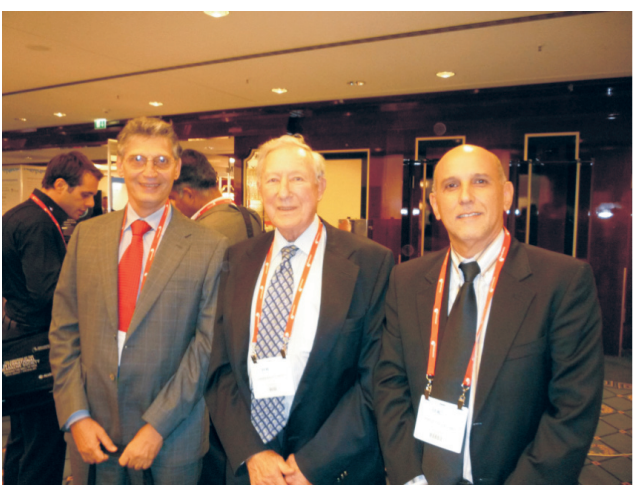

Professor James Lance with Carlos Bordini and Marcelo Valença

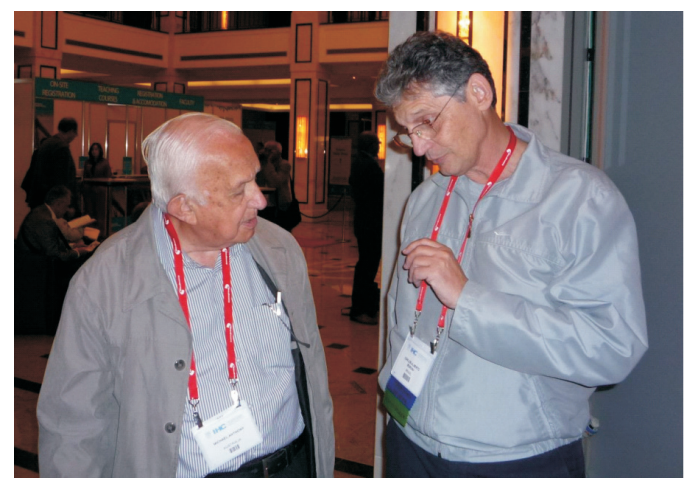

Professor Michael Anthony with Carlos Bordini 
with a new symptom is interesting, two is a coincidence and three is a paper'. I have always been a sort of collector of unusual things and have put them on the back-burner...". He has received various awards and honors throughout his academic career, particularly in the area of headache. ${ }^{2} \mathrm{He}$, in association with Curran (1964), conducted the first trial of amitriptyline to treat headache.

His University associate, Professor Anthony is well-known for his reports on the involvement of serotonin in migraine attacks ${ }^{3}$ and described the cervicogenic headache. ${ }^{4,5} \mathrm{He}$ reported that methylprednisolone injections into the region of the greater and lesser occipital nerves produced complete relief of pain in the majority of the patients with cervicogenic headache. ${ }^{5}$

In addition, in the present issue the readers will find interesting articles dealing with the association of migraine with fibromyalgia, and migraine with a special type of visual aura. The reader will notice that some of the published articles received comments from experts in the field of Headache Medicine. This is one of the ways we are trying to improve the quality of our journal. The abstracts selected to oral or poster presentation at the XXV Brazilian Congress of Headache are also published here.

\section{References}

1. Valenca MM, Andrade-Valenca LPA, Martins C. Functional anatomy of headache: circle of Willis aneurysms, third cranial nerve and pain. Headache Medicine. 2011; 2(3):82-8.

2. http://www.science.org.au/scientists/interviews/l/notes_lance.html

3. Anthony $M$, Hinterberger $\mathrm{H}$, Lance JW. Plasma serotonin in migraine and stress. Arch Neurology. 1967;16:544-5

4. Anthony M. Headache and the greater occipital nerve. Clin Neurol Neurosur. 1992; 94:297-300.

5. Anthony M. Cervicogenic headache: prevalence and response to local steroid therapy. Clin Exp Rheumatol. 2000; 18(2 Suppl 19):S59-64.

Marcelo M. Valença, MD, PhD \& Fernando Kowacs, MD, PhD 